\title{
Guillaume de Volpiano, un réformateur en son temps (962-1031) : Vita domni Wilhelmi de Raoul Glaber
}

Véronique Gazeau et Monique Goullet

\section{(2) OpenEdition \\ 1 Journals \\ Édition électronique \\ URL : https://journals.openedition.org/cem/11151 \\ DOI : 10.4000/cem. 11151 \\ ISSN : 1954-3093 \\ Éditeur \\ Centre d'études médiévales Saint-Germain d'Auxerre}

Édition imprimée

Date de publication : 15 août 2009

Pagination : 403-405

ISSN : 1623-5770

Référence électronique

Véronique Gazeau et Monique Goullet, « Guillaume de Volpiano, un réformateur en son temps (962-1031) : Vita domni Wilhelmi de Raoul Glaber », Bulletin du centre d'études médiévales d'Auxerre I BUCEMA [En ligne], 13 | 2009, mis en ligne le 08 septembre 2009, consulté le 22 septembre 2022. URL : http://journals.openedition.org/cem/11151; DOI : https://doi.org/10.4000/cem.11151

Ce document a été généré automatiquement le 22 septembre 2022.

\section{cc) (†) (2)}

Creative Commons - Attribution - Pas d'Utilisation Commerciale - Partage dans les Mêmes Conditions 4.0 International - CC BY-NC-SA 4.0

https://creativecommons.org/licenses/by-nc-sa/4.0/ 


\title{
Guillaume de Volpiano, un réformateur en son temps (962-1031) : Vita domni Wilhelmi de Raoul Glaber
}

\author{
Véronique Gazeau et Monique Goullet
}

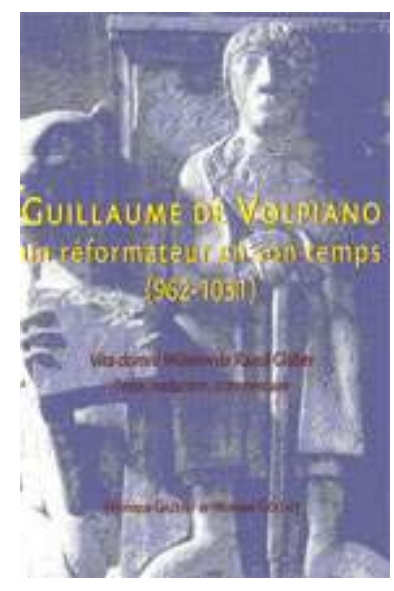

Si l'on en croit son hagiographe Raoul Glaber, Guillaume de Volpiano tint les rênes de quarante maisons bénédictines et assura la direction de douze cents moines. $\mathrm{Au}$ moment où les Capétiens succédaient aux Carolingiens et où les empereurs saxons parvenaient à éliminer les rois d'Italie qui s'étaient efforcés de faire revivre un royaume indépendant, il se trouva à la tête d'un ensemble de monastères dont le noyau se situait en Bourgogne, mais qui s'étendait bien au-delà, jusqu'en Normandie et dans le Piémont. C'est précisément en Normandie, à Fécamp, abbaye réformée par Guillaume, qu'est conservé le seul témoin manuscrit survivant de sa vita, Paris, BnF, lat. 5390, rédigé durant le 3equart du XIe siècle, peut-être à la demande de l'abbé Jean de Fécamp. Si Guillaume a depuis longtemps suscité des études savantes, en particulier celle de Neithard Bulst (Untersuchungen zu den Klosterreformen Wilhelms von Dijon (962-1031), Bonn, 1973), il manquait une traduction 
française de sa vita et un commentaire littéraire et historique solidement appuyés sur le texte lui-même. Le programme de l'agrégation - «Pouvoirs, Église et société dans les royaumes de France, de Bourgogne et de Germanie (888-début du XII siècle)» - fut l'occasion de mettre en œuvre un projet conçu de longue date par Véronique Gazeau, mais qui ne pouvait être réalisé sans la collaboration d'un(e) philologue. Notre idée commune fut donc de profiter de cette synergie pour donner à notre commentaire une double dimension: historique, bien sûr, mais aussi méthodologique, en ce sens qu'il suggère des pistes de lecture pour les textes hagiographiques.

2 Le livre s'ouvre par une brève présentation de Raoul Glaber et des circonstances de rédaction de la vita; celles-ci, pour faire l'objet d'un récit relativement détaillé, ne nous demeurent pas moins en partie obscures, et c'est là l'occasion de souligner la façon dont Raoul brouille souvent la chronologie au profit d'un récit subjectif et allusif. En revanche, sa méthode est limpide lorsqu'il travaille à construire la sainteté de l'abbé Guillaume. Sont mises en avant les «vertus » du héros, qu'elles soient ses vertus naturelles (bonne naissance, intelligence, maturité précoce), ses vertus acquises (globalement toutes les vertus d'un moine bénédictin) ou ses miracles (virtutes en latin). Sa réputation de sainteté (fama sanctitatis) se construit au fil des chapitres, mais ne sera jamais sanctionnée par quelque reconnaissance institutionnelle que ce soit : bien entendu, l'époque n'est pas encore aux procès de canonisation, mais la mémoire de Guillaume n'entrera pas non plus véritablement dans la liturgie. Cette construction hagiographique, appelée par l'intention de l'auteur, ne contrarie en rien la dimension historique de l'œuvre; est-il d'ailleurs besoin de rappeler qu'au Moyen Âge l'opposition entre les deux "genres" n'a guère de sens? À preuve la dimension hagiographique de certains passages des Histoires, et la dimension historique de certains traits de la vita, plus précise que les Histoires sur certains points.

3 Le centre du livre est constitué par la présentation philologique de la vita - c'està-dire par l'histoire de sa tradition et par la présentation du manuscrit de Fécamp -, suivie de son édition - qui va plus loin que N. Bulst dans la fidélité à celui-ci - et de sa traduction.

4 La troisième partie intéressera d'autant plus l'historien qu'il aura été convaincu par les deux précédentes : le portrait de Guillaume comme réformateur et, plus généralement, l'histoire que l'on fait de la réforme de la première moitié du $\mathrm{XI}^{e}$ siècle se comprendront d'autant mieux qu'ils ne peuvent être pour nous que la somme conjuguée de sources diplomatiques et de sources narratives forcément orientées - comme les Histoires et la Vie de Guillaume par Raoul Glaber -, mais aussi comme la Chronique de Saint-Bénigne de Dijon. Le livre aura atteint son but si le lecteur accepte l'idée d'une relative pauvreté de chaque source, pauvreté qui se mue en richesse si chacune est soutenue par la conjonction de toutes et, surtout, si toutes sont éclairées par une bonne méthode critique.

5 Derrière le récit consensuel de la vita se fait jour, en effet, le tiraillement de Guillaume entre sa fidélité à l'empereur Otton Ier, auquel son père Robert se rallie dans le premier chapitre du texte, et sa fidélité aux petits-fils de Bérenger II, le marquis d'Ivrée Arduin et le comte bourguignon Otte-Guillaume, qui tous deux, ainsi que son parent l'évêque de Langres Brunon (Brun de Roucy) et le duc Henri Ier de Bourgogne, soutinrent ses entreprises. Le texte hagiographique tente 
également d'atténuer (voire de dissimuler) les zones d'ombre que sont ses relations parfois conflictuelles avec Robert le Pieux, tout au moins avant la mort de Brunon en 1016 ; le successeur de ce dernier, Lambert, remit en effet Dijon au roi de France, et Robert devint alors un bienfaiteur de Saint-Bénigne. D'une façon générale, Guillaume joua fort habilement de sa parentèle et de ses réseaux familiaux, en gardant un subtil équilibre entre les intérêts de l'Église et les risques de se trouver en porte à faux avec elle. Le talent de ce grand réformateur, qui, avec ou sans le titre, cumula les abbatiats, fut de ne jamais s'aliéner à aucune structure: bien que sous influence clunisienne, ses maisons n'appartinrent jamais à l'Ecclesia cluniacensis, son mode de gouvernement demeura personnel et visa avant tout à cultiver les réseaux capables de procurer à chaque établissement les conditions économiques optimales pour la mise en place de la réforme spirituelle.

INDEX

Mots-clés : Guillaume de Volpiano, Raoul Glaber, vita domni Wilhelmi 